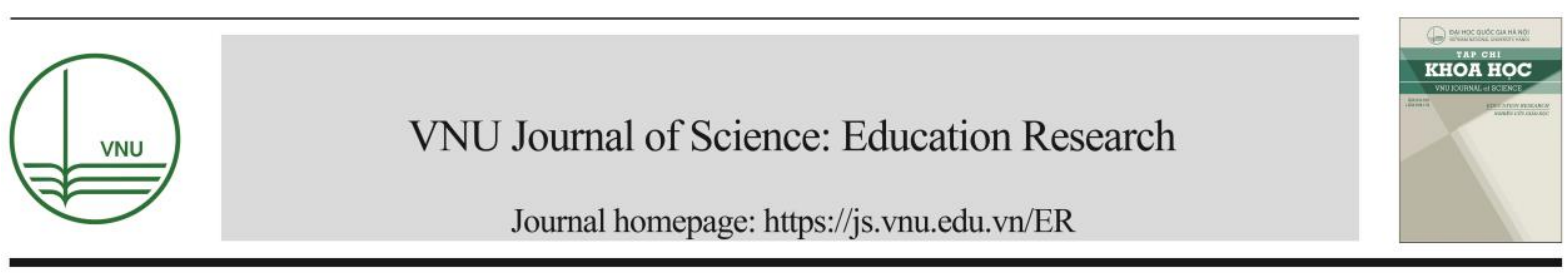

Review Article

\title{
Conceptual and Rating Model of the V-SMARTH Smart University
}

\author{
Nguyen Huu Duc ${ }^{1, *}$, Ha Quang Thuy ${ }^{1}$, Pham Bao Son ${ }^{1}$, \\ Tran Trong Hieu ${ }^{1}$, Ton Quang Cuong ${ }^{2}$ \\ ${ }^{I}$ VNU University of Engineeing and Technology, 144 Xuan Thuy, Cau Giay, Hanoi, Vietnam \\ ${ }^{2}$ VNU University of Education, 144 Xuan Thuy, Cau Giay, Hanoi, Vietnam
}

Received 04 April 2020

Revised 13 April 2020; Accepted 13 April 2020

\begin{abstract}
The conceptual model of smart university has been generalized as a digital transformation-oriented higher educational institution using digital infrastructure (digital legal, digital human resources, digital data, digital technologies and digital applications) to provide personalized learning services for learners of all generations in the country and around the world. It meets the lifelong learning requirements and sustainable development of individuals as well as nations. The smart university is described through the V-SMARTH model, which consists of 6 basic components of digital resources: open access learning materials, virtual learning environment, individualized education, interactive learning and digital platform. These elements come together in three pillars of digitization, digital learning model and comprehensive digital transformation process. The study also approaches the notions of the smartness and the readiness level of the smart university. In particular, issues of performance metrics of smart universities were developed and implemented with the UPM rating criteria for the VNU University of Engineering and Technology.
\end{abstract}

Keywords: Smart university, V-SMARTH model, digital resources, digital infrastructure, smart level, readiness level, benchmarking.

\footnotetext{
${ }^{*}$ Corresponding author.

E-mail address: ducnh@vnu.edu.vn

https://doi.org/10.25073/2588-1159/vnuer.4400
} 


\title{
Mô hình khái niệm và xếp hạng đối sánh đại học thông minh V-SMARTH
}

\author{
Nguyễn Hữu Đức ${ }^{1, *}$, Hà Quang Thụy ${ }^{1}$, Phạm Bảo Sơn ${ }^{1}$, \\ Trần Trọng Hiếu ${ }^{1}$, Tôn Quang Cường ${ }^{2}$ \\ ${ }^{I}$ Truờng Đại học Công nghệ, Đại học Quốc gia Hà Nội, 144 Xuân Thủy, Cầu Giấy, Hà Nội, Việt Nam \\ ${ }^{2}$ Truờng Đại học Giáo dục, Đại học Quốc gia Hà Nội, 144 Xuân Thủy, Cầu Giấy, Hà Nội, Việt Nam
}

Nhận ngày 04 tháng 4 năm 2020

Chỉnh sửa ngày 13 tháng 4 năm 2020; Chấp nhận đăng ngày 13 tháng 4 năm 2020

\begin{abstract}
Tóm tắt: Mô hình khái niệm về đại học thông minh đã được khái quát là một cơ sở giáo dục định hướng đổi mới sáng tạo được chuyển đổi số; sử dụng hạ tầng số (pháp lý số, nhân lực số, dữ liệu số, công nghệ số và ứng dụng số) để cung cấp dịch vụ đào tạo cá thể hóa cho người học mọi thế hệ ở trong nước và trên khắp thế giới, đáp ứng yêu cầu học tập suốt đời và phát triển bền vững của các cá nhân cũng như các quốc gia. Đại học thông minh cũng được mô tả thông qua mô hình V-SMARTH, bao gồm 6 thành tố cơ bản: tài nguyên số, học liệu truy cập mở, môi trường dạy-học ảo, nhu cầu học tập riêng, phương pháp dạy-học có tương tác và hạ tầng số. Các thành tố này qui tụ trong ba trụ cột: số hóa, mô hình dạy-học dựa trên công nghệ số và quá trình chuyển đổi số toàn diện hệ thống. Nghiên cứu còn tiếp cận các khái niệm về mức độ thông minh và mức độ sẵn sàng của đại học thông minh. Đặc biệt, vấn đề đo lường và đối sánh chất lượng của đại học thông minh đã được thử nghiệm với bộ tiêu chuẩn xếp hạng đối sánh UPM đối với Trường Đại học Công nghệ, Đại học Quốc gia Hà Nội.
\end{abstract}

Từ khóa: Đại học thông minh, đại học V-SMARTH, tài nguyên số, hạ tầng số, mức độ thông minh, mức độ sẵn sàng, đối sánh.

\section{Mở đầu}

Cùng với sự phát triển của công nghệ Web và công cuộc chuyển đổi số, đại học thông minh (Smart University) là một thiết chế giáo dục mới dựa vào các công nghệ mới nổi, đang được phát triển rất mạnh mẽ. Mô hình đại học thông minh hiện đại nhất hiện nay đã cho thấy khả năng ứng dụng thành công Internet kết nối vạn vật $(I o T)$ và các hệ thống thực-ảo (CyberPhysical System - CPS). Việc thiết kế và thực thi mô hình đại học thông minh không còn bị giới hạn bởi các giải pháp công nghệ đối với việc triển khai và quản lí đào tạo, mà cần đến

\footnotetext{
* Tác giả liên hệ.

Địa chi email: ducnh@vnu.edu.vn

https://doi.org/10.25073/2588-1159/vnuer.4400
}

một chiến lược tổng thể và mô hình mang tính tích hợp với các thiết chế xã hội, hạ tầng kinh tế, văn hóa, giáo dục ở tầm vĩ mô. Theo tiếp cận thành phố thông minh (Smart City), đại học thông minh cũng đang được quan tâm với đầy đủ các yếu tố từ mô hình khái niệm đến đặc điểm và tính năng, chương trình đào tạo và học liệu, phương pháp sư phạm, khuôn viên đại học và cơ sở hạ tầng,... Các vấn đề này đã và đang được nghiên cứu mạnh mẽ ở trên thế giới [1-5]. Ở Việt Nam, đã có một số nghiên cứu về trường học thông minh, trong đó việc mô tả khái niệm, mục tiêu và đặc điểm bước đầu đã được đề cập và thu hút được sự quan tâm nhất định của các nhà chuyên môn [6-10].

Trên cơ sở tổng quan và phân tích các nghiên cứu, bài báo này mô hình hóa khái niệm, mức độ thông minh và mức độ sẵn sàng của đại 
học thông minh; đề xuất mô hình V-SMARTH với ba trụ cột về tài nguyên số, mô hình dạy-học số và chuyển đổi số. Đặc biệt vấn đề đo lường, đối sánh cho đại học thông minh cũng được tiếp cận và triển khai áp dụng.

\section{Mô hình hóa khái niệm đại học thông minh và mức độ sẵn sàng}

\subsection{Mô hình hóa khái niệm đại học thông minh}

Đại học thông minh là một phần của thành phố thông minh. Do đó, trong nghiên cứu này các mô tả, phân tích và kiến giải mô hình hóa khái niệm đại học thông minh được viện dẫn và liên hệ trên nền tảng các đặc điểm, thuộc tính và chức năng của thành phố thông minh.

Khái niệm thành phố thông minh xuất hiện từ cuối những năm 1990 và có nhiều sự thay đổi theo thời gian. Hiện nay, khái niệm thành phố thông minh về cơ bản đã có sự thống nhất. "Thành phố thông minh bền vũng là một thành phố đổi mới sáng tạo sủ dụng các công nghệ thông tin - truyền thông (ICT) và các giải pháp công nghệ hiện đại khác để nâng cao chất luợng cuộc sống, hiệu quả hoạt động và dịch vu đô thị; nâng cao tính canh tranh, đồng thời đảm bảo đáp ứng được nhu cầu của các thế hệ hiện tại và tuoong lai về các khía cạnh kinh tế, xã họi, môi trường và văn hóa" [11]. Thành phố thông minh là nơi thực hiện chiến lược phát triển tổng thể, thống nhất dựa trên các công nghệ và giải pháp thông minh đối với 8 thành tố: Công dân thông minh, năng lượng thông minh, chăm sóc sức khỏe thông minh, tòa nhà thông minh, di động thông minh, hạ tầng thông minh, công nghệ thông minh, quản trị và giáo dục thông minh (Hình 1).

Đại học thông minh là một khái niệm liên quan đến việc hiện đại hóa và công nghệ hóa toàn diện tất cả các quy trình và hoạt động giáo dục, còn giáo dục thông minh là hoạt động trực tiếp đổi mới chất lượng đào tạo, nghiên cứu, thương mại hóa tri thức và các hoạt động khác của đại học. Về giáo dục thông minh, IBM định nghĩa như sau [2]: "Một hệ thống giáo dục liên ngành, lấy người học làm trung tâm, kết nối các co sở giáo duc và cung cấp: i) các chuoong trình học tập thich úng và điều kiện học tập tốt cho ngườ hoc; ii) công nghệ day-hoc hơp tác và tài nguyên số cho giảng viên và người hoc; iii) qui trình quản trị đượ tin hoc hóa, hoạt động trong lớp học được giám sát và báo cáo; iv) thuờng xuyên cập nhật thông tin về người hoc, v) tài nguyên học tập trục tuyến cho nguời hoc ở khắp moi nơt".

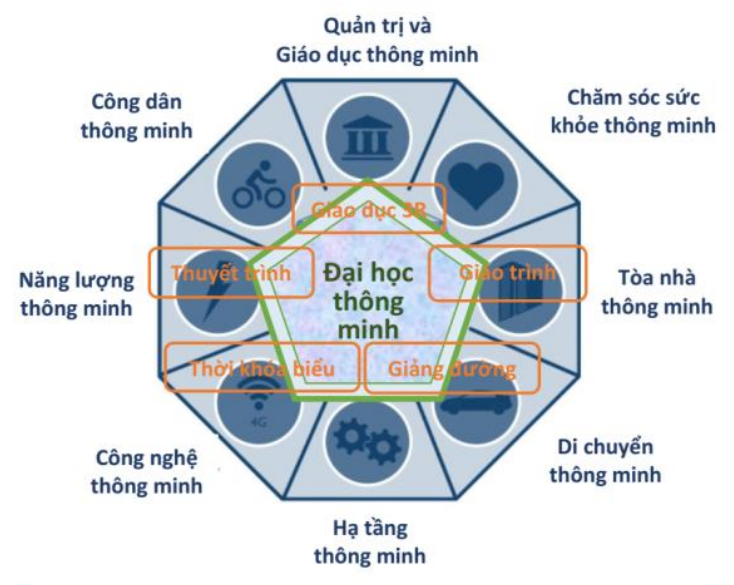

Đại học thông minh trên nền tảng thành phố thông minh

Hình 1. Đại học thông minh trên hệ thống nền của thành phố thông minh.

Theo tiếp cận kỹ thuật, Roth-Berghofer [3] mô tả đại học thông minh là "môt nền tảng thu nhận và cung cấp dũ liệu co sở để thúc đầy khả năng phân tích và đề ra giải pháp cái thiện môi truờng và chất luợng dạy và họ dựa trên truy xuất dĩ liệu cảm biến và sủ dụng dũ liệu mở được liên kết và kiến thức giảng dạy hình thức hóa". Trên cơ sở đó, Coccoli và cộng sự [4] nhấn mạnh: Đại học thông minh có đặc trưng được hồ trợ bằng công nghệ thông minh, sử dụng các công cụ và thiết bị thông minh (điển hình là thiết bị di động thông minh), mạng thế hệ mới, các ứng dụng phần mềm tương tác cao. Theo đó, giáo dục thông minh chỉ là tầng cao, tầng kết quả và hiển thị được của rất nhiều thành phần bên dưới như hạ tầng ICT, khả năng di chuyển, lưu trữ và phân phối dữ liệu, chia sẻ tri thức, quản lý năng lượng, tương tác xã hội, 
quản trị và quản lý hành chính và chăm sóc sức khỏe. Trong dự án đại học thông minh tại Đại học Trento, Italia [12], đại học thông minh còn được quan niệm là "một nền tảng đa dạng cung cấp dịch vu được cá nhân hóa cho sinh viên đại học trong nước và trên khắp thế giới". Như vậy, giáo dục thông minh đặt trong đại học thông minh cũng gần như được đặt trong mối liên hệ với các thành phần của thành phố thông minh (Hình 1).

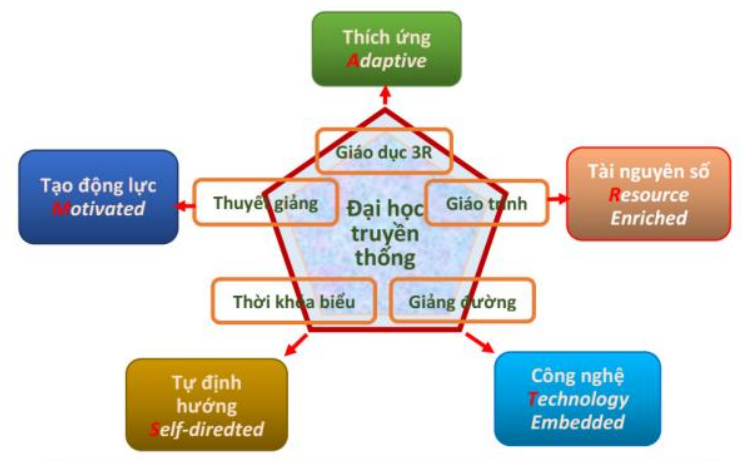

Mô hình chuyển đối từ giáo dục truyền thống sang giáo dục $K$-SMART

Hình 2. Quá trình chuyển đổi mô hình đại học truyền thống sang mô hình đại học K-SMART của Hàn Quốc. Tổng hợp và phát triển từ [14].

Trên cơ sở tổng hợp và phân tích vừa nêu, kết hợp với sứ mệnh và đặc điểm của đại học thế hệ thứ ba trong thời kỳ Cách mạng công nghiệp 4.0 [8], có thể đưa ra một định nghĩa mới về đại học thông minh: "Đại học thông minh là một cơ sở giáo duc định hướng đổi mới sáng tạo được chuyển đổi số; sủ dụng hạ tầng số (pháp lý số, nhân lự số, dũ liệu số, công nghệ số và ứng dụng số) để cung cấp dịch vu đào tạo cá thể hóa cho người họ mọi thế hẹ ở trong nuớc và trên khắp thế giới, đáp úng yêu cầu học tập suốt đời và phát triển bền vũng của các cá nhân cũng như các quốc gia".

Mô hình đại học thông minh như vậy rõ ràng có liên quan chặt chẽ đến các yếu tổ nền tảng của thành phố thông minh (Hình 1), có mục tiêu và thích ứng với yêu cầu Cách mạng công nghiệp 4.0. Trong định nghĩa này, thành tố đại học định hướng đổi mới sáng tạo là bản chất và động lực phát triển quyết định nội dung và mục tiêu đào tạo $[6,8]$; còn thành tố đại học thông minh là hệ thống nền, là phương thức và công cụ thực hiện. Xây dựng đại học thông minh thực chất là thực hiện quá trình chuyển đổi số để thay đổi phương thức hoạt động học thuật truyền thống sang phương thức hoạt động học thuật dựa trên các phiên bản số của các thực thể và kết nối của chúng trong không gian số [13]; đáp ứng mục tiêu cá nhân và nhu cầu học tập suốt đời và do đó góp phần nâng cao chất lượng và tạo ra những giá trị mới của quá trình đào tạo.

Theo tiếp cận đã nêu, Hàn Quốc đã đưa ra sáng kiến giáo dục để chuyển đồi mô hình giáo dục truyền thống giáo dục $3 \mathrm{R}$ (năng lực đọc, viết và tính toán - Reading, wRiting và aRithmetic) với giáo trình giấy truyền thống; không gian - phòng học thực (giảng đường); thời khóa biểu cố định và phương pháp sư phạm thuyết giảng) thành mô hình giáo dục "Tự định hướng, Tạo động lực, Thích ứng, Giàu tài nguyên, Dựa trên công nghệ" (Self-directed, Motivated, Adaptive, Resource enriched, Technology, viết tắt là mô hình SMART) [14].

Để so sánh với mô hình mà bài báo này đề xuất cho Việt Nam, mô hình chuyển đổi giáo dục của Hàn Quốc được ký hiệu lại là K-SMART (Hình 2). Đây là mô hình đơn giản, cơ bản về giáo dục thông minh, được UNESCO coi như một ví dụ điển hình về chính sách cải thiện hệ thống giáo dục quốc gia của chính phủ, định hướng việc xây dựng môi trường học tùy biến (cá nhân hóa) và hiệu quả cho người học ở Thế kỷ 21 [5]. Sáng kiến K-SMART tập trung vào ba nội dung. Thư nhất là phương pháp sư phạm mới, không chỉ giải quyết các chữ (đọc, viết) và số (tính toán) mà giải quyết cả vấn đề âm thanh và hình ảnh cùng với tất cả các công nghệ đa phương tiện khác. Thư hai, người dạy và người học có tầm quan trọng như nhau trong lớp học. Thú $b a$, môi trường học tập giàu tài nguyên số, được triển khai qua công nghệ điện toán đám mây. Ở đó, người dạy và người học có thể tự do sản xuất nội dung, học liệu số và tải lên, tải xuống một cách an toàn phục vụ cho việc học tập và nghiên cứu. Đây chính là thế mạnh của Web 2.0 đã trình bày ở phần đầu. Thiết nghĩ, đây là phương châm, nội dung và 
cách đi hiệu quả mà các quốc gia đang phát triển có thể áp dụng.

\subsection{Mức độ thông minh của đại học thông minh}

Đại học thông minh có sáu đặc trưng là: khả năng thích ứng (adaptation), khả năng thu nhận thông tin (sensing), khả năng chuyển đổi thông tin thành cơ sở dữ liệu, số hóa (infering), khả năng phân tích, chẩn đoán (self-learning), khả năng dự báo (anticipation), khả năng tối ưu hóa (self-optimization or re-structuring) [15]. Đó cũng được coi là sáu mức thông minh sắp xếp tăng dần từ thấp lên cao của đại học thông minh. Tuy nhiên, khi xem xét và phân tích kỹ có thể thấy rằng mức độ đầu tiên (thích ứng) và cuối cùng (tối ưu hóa) là điểm đầu tiên và cuối cùng khi thực hiện một chu trình. Điểm cuối của chu trình này có thể là điểm xuất phát của chu trình mới; chúng có nhiều điểm tương đồng nên có thể tích hợp vào làm một. Đề xuất này phù hợp với thiết kế kiến trúc của các hệ thống CPS [6, 16-17].

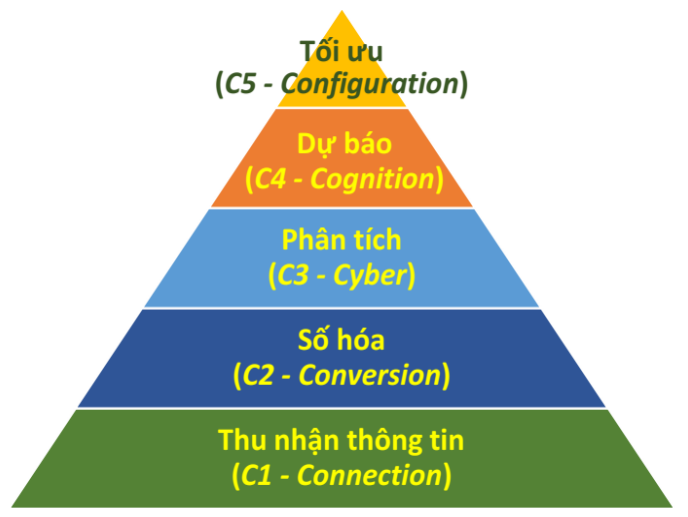

Hình 3. Cấu trúc $5 \mathrm{C}$ của các hệ thống $\mathrm{CPS}$ và các mức độ thông minh của đại học thông minh. Tổng hợp và phát triển từ [6].

Các hệ CPS là đặc trưng tiêu biểu của môi trường công nghiệp 4.0 , là cơ sở để thiết kế và xây dựng các mô hình nhà máy thông minh. CPS thường được thiết kế với cấu trúc $5 \mathrm{C}$ (Connection - thu nhận và kết nối thông tin, Conversion - chuyển đổi thông tin và số hóa, Cyber - phân tích và chẩn đoán, Cognition - nhận diện và dự báo, Configuration - tối ưu hóa). Khi áp dụng vào giáo dục đại học, thiết kế và chức năng của $\mathrm{CPS}$ được mô tả trên Hình 3 [6]. Theo đó, các chức năng và đặc trưng của đại học thông minh đã nêu ở trên có thể tích hợp lại và đều được đáp ứng thông qua 5 lớp cấu trúc này:

- Mô đun thu nhận và kết nối thông tin (Connection - Sensing, C1) là năng lực thu nhận và quản lý thông tin về tất cả đối tượng, sự kiện, quá trình và cả tác động đến tất cả các hoạt động và trên mọi địa điểm trong khuôn viên đại học. Hệ thống thông tin này bao gồm: hệ thống cảm biến thu nhận dữ liệu về việc sử dụng năng lượng, ánh sáng, nhiệt độ, độ ẩm, an toàn, an ninh; hệ thống đầu đọc thẻ thông minh (hoặc sinh trắc học) để mở cửa cho các giảng đường, phòng máy tính, lớp học thông minh và kích hoạt các thiết bị, phần mềm; hệ thống nhận diện khuôn mặt, giọng nói, cử chỉ và các thiết bị tương ứng để truy xuất và xử lý dữ liệu về việc tham gia lớp học của sinh viên, hoạt động của lớp học, của giảng viên và cả thông tin do giảng viên và sinh viên cing cấp, ví dụ về kết quả kiểm tra, đánh giá học tập (câu hỏi, bài kiểm tra và bài tập trong lớp). Điều quan trọng là các công nghệ thu nhận thông tin này không sử dụng một cách độc lập, riêng lẻ mà được liên kết, trong đó IoT, điện toán đám mây, chuỗi khối đã kết nối, lưu trữ các thông tin tạo nên hạ tầng dữ liệu lớn. Thêm vào đó, hệ thống mạng không dây cho phép chuyển tải chúng trong không gian mạng.

- Mô đun chuyển đổi thông tin - số hóa (Conversion - Infering, C2): Hệ thống có thể thu nhận tất cả thông tin từ mô đun kết nối để xử lý, số hóa và đưa ra kết quả thống kê, ví dụ về kết quả điểm danh và tình hình học tập của sinh viên, cập nhật hồ sơ sinh viên; chất lượng bài giảng thông qua kết quả trả lời các câu hỏi kiểm tra; tình hình sử dụng giảng đường, phòng thí nghiệm; mức độ và sự phân bổ giờ giảng cho giảng viên.

- Mô đun phân tích và chẩn đoán (Cyber Self-learning, C3): Cho phép theo dõi sự chuyên cần và tiến bộ của sinh viên trong quá trình học tập môn học, mức độ hài lòng của sinh viên và khảo sát trực tuyến về chất lượng 
bài giảng, trên cơ sở đó phân tích và chẩn đoán sinh viên có thể hoàn thành học phần hay không; về hiệu quả của việc bố trí lịch giảng dạy cho môn học; hiệu quả sử dụng năng lượng,... Hiện nay, khả năng phân tích, khai thác và sử dụng dữ liệu không chỉ được thực hiện bởi các phần mềm truyền thống mà đã được hỗ trợ của trí tuệ nhân tạo $(\mathrm{AI})$. Điều này cũng góp phần lý giải cho thuật ngữ tiếng Anh cyber được sử dụng trong mức độ thông minh này. Đối với việc hoạt động dạy-học, mô đun này có thể thực hiện qua chức năng phân tích quá trình dạy-học (learning analytics) trong hệ thống quản lý dạy-học (learning management system - LMS) sẽ được trình bày trong phần 3.

- Mô đun nhận diện và dụ báo (Cognition Anticipation, C4): Sau quá trình phân tích, các thông tin về hiệu quả của việc phẩn bổ và sử dụng cơ sở vật chất, đầu tư, điều chỉnh chương trình đào tạo,... sẽ được đánh giá. Trên cơ sở đó, các giải pháp cải tiến sẽ được đề xuất. Đặc biệt, đây còn là năng lực dự báo các rủi ro có thể xảy ra và giải pháp phòng ngừa về an ninh, tình hình tuyển sinh, mức độ tham gia học tập.

- Mô dun tối uu hóa (Configuration and Adaptation, C5): Là các giải pháp tổ chức lại để nâng cao hiệu quả và chất lượng đào tạo, trong đó có đổi mới môi trường dạy-học; phương pháp dạy-học linh hoạt có tương tác, truyền thông xã hội; học tập cá thể hóa và gần đây là việc đầu tư mô hình các nhà máy thông minh cho phép sinh viên triển khai mô phỏng ý tưởng đến chế thử tại phòng thí nghiệm; điều kiện ánh sáng, môi trường,... Đặc biệt, đại học thông minh còn có năng lực tự động thay đổi cấu hình nội tại, tự tái tạo và tự duy trì theo chủ đích trong các điều kiện thích hợp mà không có tác nhân, thực thể bên ngoài tác động. Ví dụ như tự động cấu hình hệ thống, tham số hiệu năng, cảm biến, bộ truyền động và các tính năng thông minh khác trong giờ học theo hồ sơ của giảng viên; tự động đóng và phục hồi trong trường hợp mất điện tạm thời; tự động cấu hình lại mạng cảm biến không dây phù hợp với mức độ sử dụng. Thậm chí, đại học thông minh cũng có năng lực tự động sửa đổi các chức năng nghiệp vụ, điều kiện day-học mới, dễ dàng thích ứng với nhu cầu của sinh viên khuyết tật (hệ thống chuyển văn bản thành giọng nói hoặc ngược lại, hệ thống tìm kiếm, điều khiển bằng giọng nói,...) và dễ dàng thích ứng mạng với các nền tảng kỹ thuật mới.

Cấu hình thiết kế và các mức độ thông minh như vậy được biểu diễn trên Hình 3.

\subsection{Mức độ sãn sàng của đại học thông minh}

Để giúp các cơ sở đại học hình dung rõ ràng hơn lộ trình chuyển đổi từ mô hình đại học truyền thống tới mô hình đại học thông minh, trên cơ sở phát triển mô hình năng lực trưởng thành tích hợp (Capability Maturity Model Integration: CMMI) [18] trong phát triển phần mềm, Heinemann và Uskov [19] đã đề xuất và phát triển mô hình trưởng thành thông minh (Smart Maturity Model: SMM).

Theo mô hình trưởng thành thông minh này, đại học thực hiện giáo dục thông minh có năm mức độ sẵn sàng: Khởi đầu, Hoàn thiện, Tiêu chuẩn hóa, Định lượng hóa và Tối uu hóa (Hình 4).

Ở mức Khởi đầu (mức sẵn sàng thấp nhất $-R I$ ), mới có nhóm với khoảng $2-3 \%$ giảng viên - nhà đổi mới triển khai các hoạt động theo phương châm "đề xuất và thử nghiệm" một số trong nội dung đã mô tả trong mô hình K-SMART và theo các mức độ $5 \mathrm{C}$ ở trên.

Ở mức Hoàn thiện (mức sẵn sàng thứ hai $R 2$ ), đã có thêm nhóm giảng viên tiên phong tiếp nhận (chiếm khoảng 13-15\% giảng viên) tham gia cùng nhóm giảng viên - nhà đồi mới tiến hành các hoạt động theo phương châm "Phân tích dữ liệu và hoàn thiện", thực hiện lặp các công cụ và phương pháp đổi mới đối với nhiều đổi tượng người học, theo các địa điểm và trên các thiết bị đặt khác nhau, theo các chuyên ngành khác nhau; phân tích và đánh giá kết quả thu được; tổng quát hóa kinh nghiệm triển khai.

Ở mức Tiêu chuẩn hóa (mức sẵn sàng thứ ba - R3), ngoài các giảng viên - nhà đổi mới, giảng viên tiên phong tiếp nhận đổi mới sớm, có thêm khoảng $30-35 \%$ giảng viên nữa và các nhóm cán bộ quản lý tham gia các hoạt động theo phương châm "Phát triển và thực thi tiêu 
chuẩn" để xây dựng và hình thành các tiêu chuẩn, tiêu chí đánh giá nhằm chuẩn hóa các hoạt động.

Ở mức Định luợng hóa (mức sẵn sàng thứ tư - $R 4$ ), hầu hết giảng viên và cán bộ quản lý tham gia. Các hoạt động triển khai theo phương châm "Đánh giá, kiểm soát và quản lý", nhằm xác định các chỉ số định lượng cho các tiêu chuẩn, tiêu chí, làm cơ sở đánh giá hiệu quả.

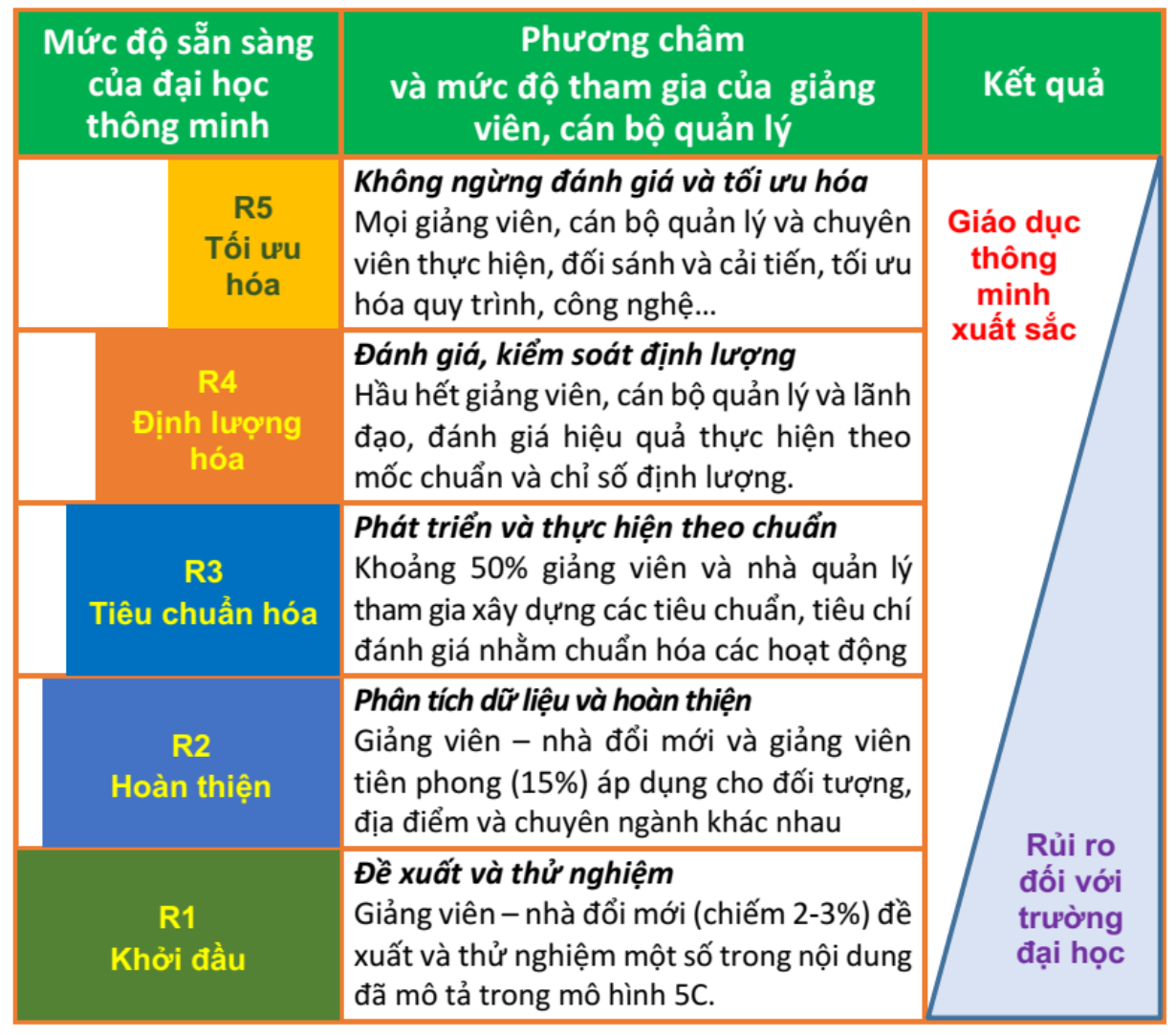

Hình 4. Các mức độ sẵn sàng của đại học thông minh. Phát triển từ [19].

Ở mức Tối uu hóa (mức sẵn sàng cao nhất $R 5)$, toàn bộ giảng viên, cán bộ quản lý và chuyên viên của trường đại học tiến hành các hoạt động theo phương châm "Liên tục đánh giá và tối ưu hóa". Đây như là một hoạt động đảm bảo chất lượng bên trong, bao gồm việc liên tục đánh giá kết quả hiện thời, giảng dạy thông minh, học thông minh, sư phạm thông minh và phân tích so sánh "kết quả dự kiến so với thực tế"; phân tích nguyên nhân và giải pháp, chỉnh sửa và/hoặc tối ưu hóa các nhược điểm hoặc điểm yếu đã xác định; liên tục cải tiến các chức năng nghiệp vụ chính; liên tục cải tiến công tác quản lý và quản trị.
Mặc dù luôn luôn cổ súy đạt được mức sẵn sáng cao nhất, nhưng mô hình trưởng thành thông minh cũng chỉ ra rằng để tối ưu hóa về mặt hiệu quả, đặc biệt là hiệu quả chi phí, các nhóm giảng viên cụ thể chỉ nên bắt đầu tham gia vào giáo dục thông minh ở các mức sẵn sàng phù hợp.

\section{Mô hình đại học thông minh V-SMARTH}

So sánh với các quốc gia trên thế giới, Việt Nam có cơ sở hạ tầng công nghệ thông tin và viễn thông được xây dựng khá đồng bộ. Vùng 
phủ sóng di động đạt $99,7 \%$ dân số trên cả nước. Trong đó, vùng phủ sóng $3 \mathrm{G}, 4 \mathrm{G}$ đạt trên $98 \%$ với mức cước phí thấp. Mạng $5 \mathrm{G}$ đã được cấp phép thử nghiệm và dự kiến triển khai thương mại từ năm 2020. Tuy nhiên, các ứng dụng vào công nghệ thông tin nói riêng và các công nghệ 4.0 trong giáo dục và đào tạo còn chậm, chưa cơ bản, chuyên nghiệp và đồng bộ, đặc biệt đang thiếu vắng một thiết kế về chiến lược và nội dung. Các cơ sở giáo dục đại học Việt Nam cần thực hiện công cuộc chuyển đổi số để từng bước xây dựng đại học thông minh với 3 trụ cột:

- Số hóa: Tạo ra biểu diễn số của các thực thể vật lý, đặc biệt là nguồn học liệu;

- Đổi mới mô hình hoạt động: đổi mới phương thức quản lý và dạy-học dựa trên các công nghệ số;

- Chuyển đổi: chuyển đổi toàn diện tư duy, văn hóa và phương thức lãnh đạo, quản lý và tổ chức phù hợp với mô hình dạy-học mới.

Trên cơ sở phát triển mô hình K-SMART về mục tiêu của đại học thông minh, đối sánh với tình hình cụ thể và điểm xuất phát của các cơ sở giáo dục đại học nước ta, mô hình V-SMARTH về nội dung và nhiệm vụ của đại học thông minh ở Việt Nam đã được đề xuất như trên Hình 5 . Theo mô hình này, đại học V-SMARTH có 6 đặc trưng: $i) S$ - tài nguyên

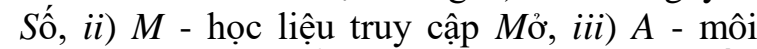
trường dạy - học $A \mathrm{o}$, (iv) $R$ - đáp ứng nhu cầu học tập Riêng, v) $T$ - phương pháp dạy - học có Tương tác và vi) $H$ - có $H a$ a tầng số. Nội dung của các thành tố này được mô tả trong Bảng 1 và Hình 5.

$S$ - Tài nguyên, học liệu số là yếu tố cơ bản của đại học thông minh V-SMARTH và dạy - học trực tuyến, trong đó, giáo trình số (digital textbook) là cốt lõi. Khác với giáo trình điện tử (e-textbook), giáo trình số cho phép tích hợp các học liệu tham khảo; thực hiện các hoạt động tương tác, kiểm tra, đánh giá với các học liệu đa phương tiện, các học liệu bổ sung, tăng cường. Ngoài ta, với giáo trình số, người học (không cần thiết có thêm tài liệu tham khảo và bài tập khác) có thể trực tiếp theo dõi, quản lý quá trình và kết quả học tập, đánh giá và kiểm tra; cho phép kết nối với nguồn học liệu bên ngoài, trên toàn thế giới. Đặc biệt, theo triết lý giáo dục và các phương pháp dạy-học hiện nay, cả người học và người dạy đều có thể (và có trách nhiệm) phát triển tài nguyên học liệu số. Ngoài ra, tài nguyên số còn do các bên liên quan cung cấp, chia sẻ.

Bảng 1. Nội dung của mô hình đại học thông minh V-SMARTH

\begin{tabular}{|c|c|c|}
\hline Viết tắt & Khái niệm & Nội dung \\
\hline $\mathbf{S}$ & Tài nguyên Số & $\begin{array}{l}\text { - Tài nguyên số nội sinh, giáo trình số “đa giác quan hóa”; } \\
\text { giảng viên và sinh viên cùng phát triển tài nguyên học } \\
\text { thuật. } \\
\text { - Tài nguyên số ngoại sinh từ các nhà xuất bản, thư viện } \\
\text { bên ngoài. } \\
\text { - Tần suất sử dụng nội bộ, bên ngoài }\end{array}$ \\
\hline M & Nội dung giáo dục Mở & $\begin{array}{l}\text { - Hoc liêuu mở; thông tin mở } \\
\text { - Bài giảng trực tuyến MOOC } \\
\text { - Chương trinh đào tạo mở } \\
\text { - Nội dung di động } \\
\text { - Mức độ được các đại học khác kết nối và sử dụng }\end{array}$ \\
\hline A & Môi trường giáo dục & $\begin{array}{l}\text { - Đào tạo trực tuyến: các lớp đào tạo trực tuyến tích hợp, } \\
\text { lớp môn tự chọn, lớp tăng cường, lớp ghi danh, luyện tập } \\
\text { ớ nhà } \\
\text { - Mô phỏng thực tế - ảo, thực tế hỗn hợp, thực tế - ảnh... } \\
\text { - Giám sát, kiểm tra đánh giá trực tuyến: giám sát quá } \\
\text { trình học tập; kiểm tra, đánh giá kết quả học tập. }\end{array}$ \\
\hline $\mathbf{R}$ & Nhu cầu học tập Riêng & $\begin{array}{l}\text { - Dạy-học theo chương trinh xác định (trực tiếp và trực } \\
\text { tuyến); dạy học trên thiết bi di động } \\
\text { - Dạy-học theo định hướng cá nhân (năng lực, lộ trình, sở } \\
\text { thích, nhu cầu...) } \\
\text { - Dạy-học ngẫu nhiên, theo các chứng chỉ micro-nano } \\
\text { - Học tập suốt đời }\end{array}$ \\
\hline $\mathbf{T}$ & $\begin{array}{l}\text { Môi trường giáo dục } \\
\text { có Tương tác }\end{array}$ & $\begin{array}{l}\text { - Hoạt động của chủ thể và các đặc tính tương tác được số } \\
\text { hóa } \\
\text { - Day-học có tương tác và hợp tác } \\
\text { - Tương tác của người học và học liệu số } \\
\text { - Tương tác, trao đổi trong nhóm môn học } \\
\text { - Văn hóa trich dẫn, đạo đức học thuật, bản quyền, sở hữu } \\
\text { tri tuệ }\end{array}$ \\
\hline H & Hạ tầng số & $\begin{array}{l}\text { - Hạ tầng pháp lý số } \\
\text { - Hạ tầng nhân lực số } \\
\text { - Hạ tầng dữ liệu số } \\
\text { - Hạ tầng công nghệ kỹ thuật số } \\
\text { - Hạ tầng ứng dụng số }\end{array}$ \\
\hline
\end{tabular}

M - Khả năng truy cập mở của tài nguyên số là đặc điểm quan trọng để thực hiện sứ mệnh của đại học thông minh về đào tạo linh hoạt và cá thể hóa. Nếu có nguồn tài nguyên phong phú nhưng không chia sẻ thì việc thực hiện mục tiêu chuyển đổi từ đại học truyền thống sang đại học thông minh không thực hiện được. Nội dung giáo dục mở bao gồm: Học liệu mở; thông tin mở, bài giảng trực tuyến MOOC, chương trình đào tạo mở và nội dung di động,... Ngoài việc đo lường mức độ sử dụng nội bộ, chất lượng và hiệu quả của tài nguyên số của trường đại học còn được đánh giá bằng mức độ được các đại 
học khác kết nối và sử dụng. Để thực hiện khả năng truy cập mở của tài nguyên số, như sẽ trình bày dưới đây, việc xây dựng văn hóa chia sẻ và thực thi đạo đức khoa học là rất cần thiết.

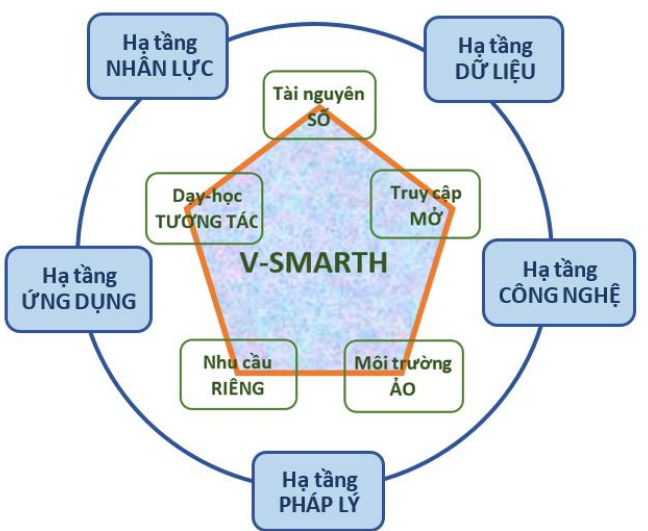

Hình 5. Mô hình đại học thông minh V-SMARTH: Nội dung giáo dục SMART trên nền tảng hạ tầng $\mathrm{H}$.

A - Môi truờng giáo duc ảo áp dụng cho cả hoạt động dạy-học và kiểm tra đánh giá. Về dạy-học, trước hết, đó là mô hình lớp học hỗn hơp (blended) b-SMARTH trong các phòng học thông minh áp dụng cho lớp học chung, lớp học đặc biệt, lớp học tích hợp và lớp học trải nghiệm sáng tạo. Mô hình này sử dụng các phương pháp dạy-học khác nhau như dạ-học dựa trên vấn đề, dạy-học theo dự án, thảo luận, dạy-học hội tụ và tích hợp liên ngành, dạy-học qua trải nghiệm. Mô hình b-SMARTH cung cấp các cơ hội cho giảng viên, chuyên gia thỉnh giảng và người học giao tiếp với nhau. Trong đó, mô hình lớp học chung là các lớp học thông thường triển khai mô hình học tập lấy người học làm trung tâm. Lớp học đặc biệt được thiết kế áp dụng đáp ứng với năng lực, trình độ của các nhóm người học đặc thù từ các lớp môn học, các lớp học tích hợp, và đặc biệt là các lớp môn học đặc thù (âm nhạc, thư viện,...). Mô hình lớp học tích hợp có thể thực hiện để kết hợp việc kết nối, trao đổi với các trường đối tác quốc tế và lớp học quy mô nhỏ hoặc ở xa khuôn viên nhà trường. Cuối cùng, mô hình lớp học trải nghiệm sáng tạo nghiệm được phát triển để hỗ trợ kinh nghiệm và sở thích đa dạng của sinh viên. Điều đặc biệt lưu ý là, trong b-SMARTH này, giáo trình số được sử dụng (Hình 6).
Thư hai, mô hình dạy-học trục tuyến e-SMARTH (Hình 7) được sử dụng để triển khai các môn học tự chọn, môn học tăng cường, xác nhận tham gia lớp học hoặc tự tăng cường, bổ sung thêm kiến thức ở nhà,... Lớp học môn học tự chọn là lớp học không được triển khai trực tiếp (off-line) tại trường, tạo điều kiện cho người học tham gia vào các lớp học theo sự lựa chọn của riêng của cá nhân. Khóa học tăng cường được tổ chức để hỗ trợ quyền học tập của các sinh viên phải chuyển trường hoặc đi học trao đổi tín chỉ. Lớp học ghi danh áp dụng để thay thế lớp học thông thường trong trường hợp sinh viên không thể tham dự do các thảm họa quốc gia, bệnh tật hoặc nhập viện dài hạn. Cuối cùng, các khóa học nâng cao, bổ sung sau giờ học là một mô hình giảng dạy nâng cao năng lực quản lý học tập của sinh viên bằng cách cho phép học tập nâng cao ở nhà. Trong mô hình e-SMARTH có các thành phần sau đây tham gia: Giảng viên dạy trực tuyến phụ trách việc hướng dẫn học tập, phát triển học liệu, giao bài tập, đánh giá các hoạt động và kết quả học tập; Cán hộ hỗ trợ lớp học trực tuyến: Quản lý sự tham gia, hỗ trợ hoạt động học tập, cập nhật thông tin lớp học và hỗ trợ học liệu ôn tập, kiểm tra, đánh giá; Cán bộ quản lý việc đăng ký lớp học: Hướng dẫn và tư vấn việc đăng ký, chấp nhận và quản lý kết quả đăng ký; Các phương pháp dạy-học áp dụng trong mô hình e-SMARTH là dạy-học cá thể hóa, dạy-học hợp tác, dạy-học phân hóa theo trình độ, năng lực và dạy-học qua giao tiếp xã hội.

Trong thời kỳ Cách mạng công nghiệp 4.0, yếu tố quan trọng và khác biệt của môi trường giáo dục ảo là các không gian học tập ảo (đặc biệt là các phòng thí nghiệm ảo, thư viện ảo và các thiết bị học tập ảo), đồng thời, đại học ảo tạo ra các cộng đồng học tập ảo. Phòng thí nghiệm ảo cho phép người học thực hiện các thí nghiệm ảo theo các kịch bản của thực tại ảo để cung cấp các cơ hội trải nghiệm thực tiễn mới trong giáo dục, tạo điều kiện cho người học dễ dàng có được trải nghiệm tương tự như trong phòng thí nghiệm thực, góp phần hình thành các kĩ năng của người học theo yêu cầu của Cách mạng công nghiệp 4.0. Hơn nữa, thí 
nghiệm ảo cũng cung cấp một mô hình nghiên cứu khám phá phi rủi ro tránh được các rủi ro có thể trong thí nghiệm thực giúp sinh viên hình dung được các quy trình phức tạp và trừu tượng. Đặc biệt, tiếp cận đại học ảo rất phù hợp đối với các nước có thu nhập thấp [6].

Giám sát, kiểm tra đánh giá trực tuyến là một trong các thành tố chính của dạy-hoc thông minh. Điều này hoàn toàn khả thi nhờ sự thông minh của môi trường dạy-học ảo. Môi trường dạy-học thông minh (smart learning environment - SLE) có khả năng ghi lại từng chi tiết về hành vi học tập của sinh viên; cho phép các bên liên quan khác nhau như người hướng dẫn, người học, giảng viên, nghiên cứu viên, cơ sở giáo dục thu nhận được các thông tin quan trọng và có giá trị thông qua việc phân tích các hành vi này. SLE có khả năng nhận diện bối cảnh, bao gồm kiến thức đã có của người học, phương pháp học tập, tốc độ học tập, các hoạt động hiện tại, mục tiêu và kết quả đầu ra, thời gian cho phép, địa điểm và sở thích cá nhân. Tất cả các thông tin thu thập được về các hành vi học tập của sinh viên và sự tương tác của chúng với các bối cảnh khác nhau được phân tích để nhận diện tình hình. Thêm vào đó, các công cụ phân tích học tập (learning analysis system - LAS) thường được cung cấp trong các hệ thống quản lý dạy-hoc (learning management system - LMS). Ví dụ như Moodle cho phép đánh giá kết quả đầu ra của môn học và cả quá trình tiến bộ trong học tập của sinh viên như: sự chuyên cần, mức độ tham gia và hoàn thành các hoạt động, đánh giá tổng quan về khóa học và phân tích thái độ tham gia, đóng góp của người học trong quá trình học tập. Do đó, SLE phân tích và đo lường, đánh giá kết quả học tập khóa học và dự đoán thành công của sinh viên [20].

$R$ - Giáo dục cá thể hóa củng cố tính linh hoạt của hệ thống giáo dục và thực hiện việc học tùy chỉnh gắn liền với sở thích cá nhân và nghề nghiệp trong tương lai. Các trường học phát triển từ nơi truyền thụ kiến thức đến các không gian kiến tạo việc học tập cá nhân để thúc đẩy năng lực và năng khiếu của người học. Khi đó, việc dạy-học theo chương trình xác định (trực tiếp và trực tuyến) có thể kết hợp với dạy-học theo định hướng cá nhân (năng lực, lộ trình, sở thích, nhu cầu,...), dạy học trên thiết bị di động.

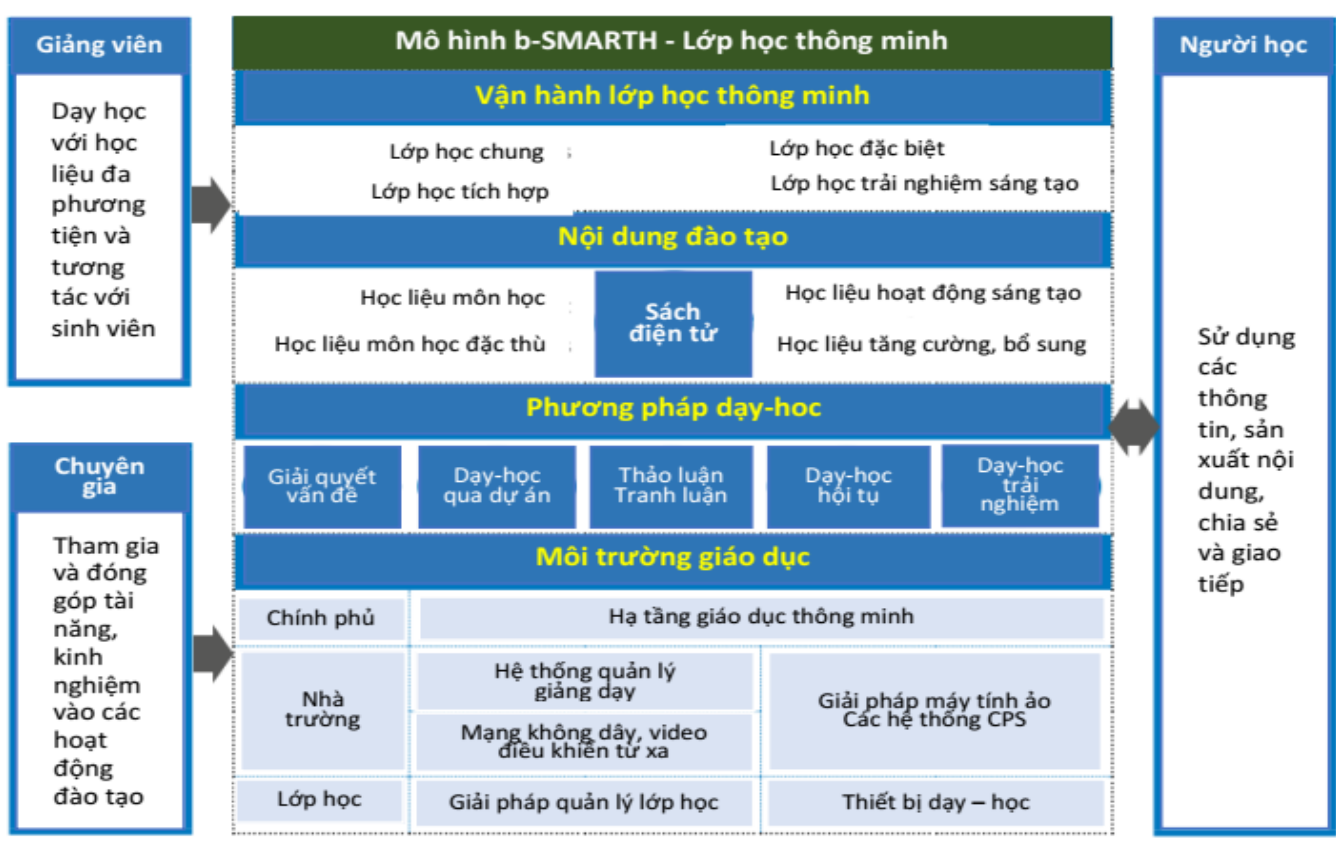

Hình 6. Mô hình dạy học kết hợp trực tiếp - trực tuyến b-SMARTH với phòng học thông minh. Tổng hợp từ [5]. 

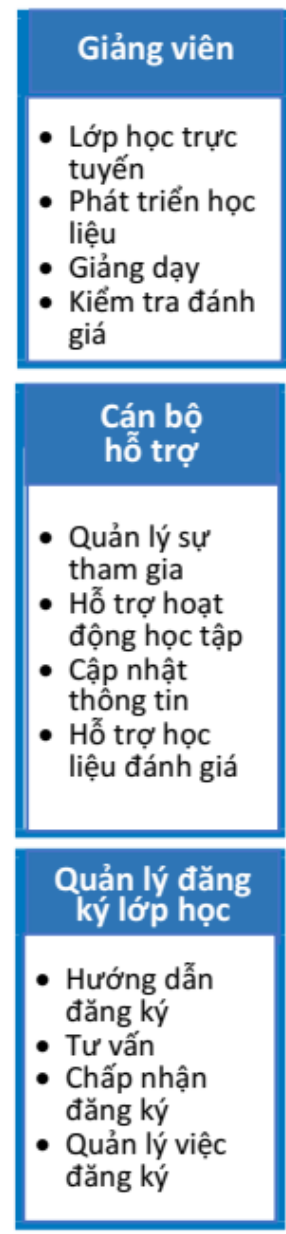

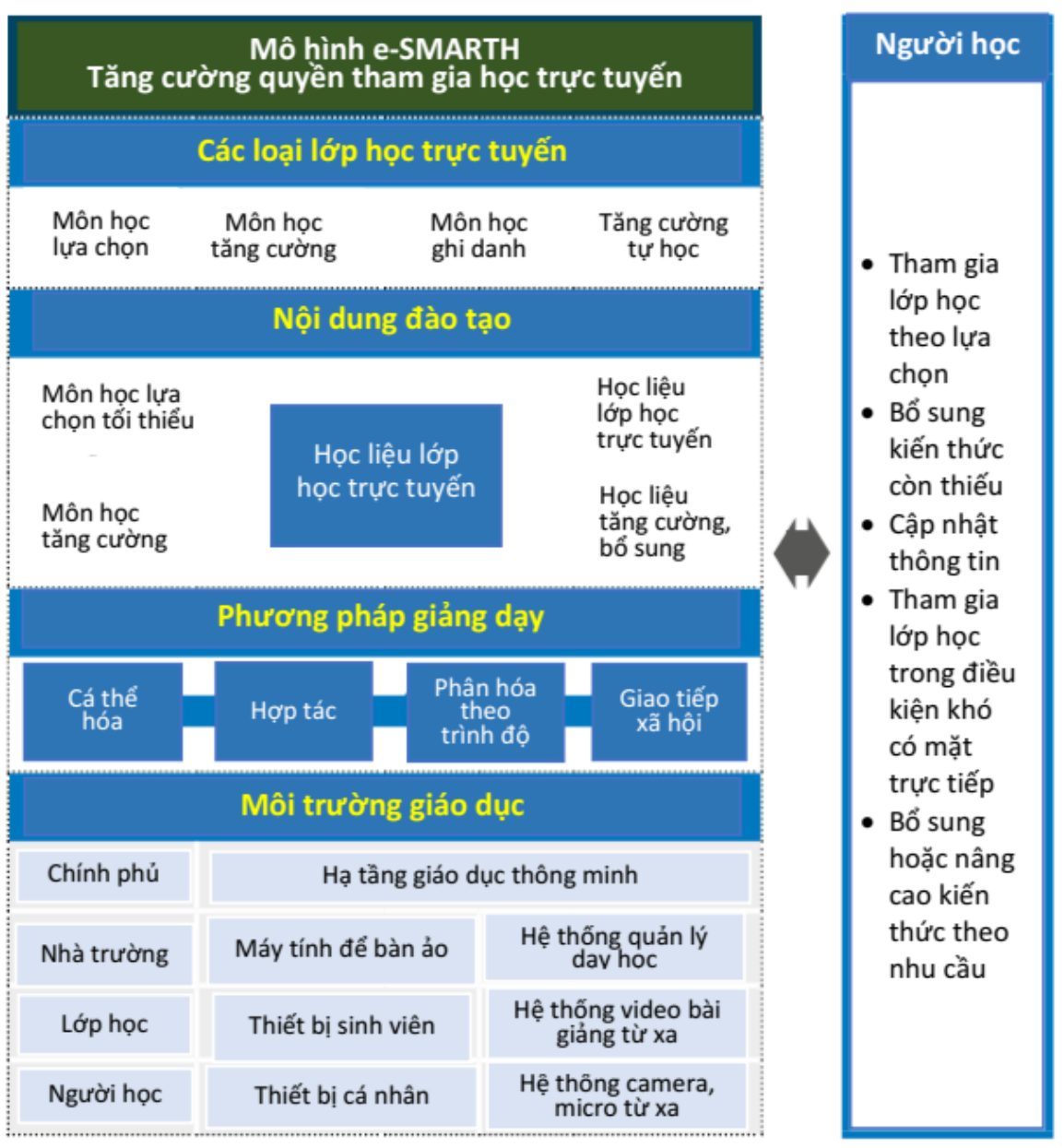

Hình 7. Mô hình dạy học kết hợp trực tuyến e-SMARTH với phòng học thông minh. Tổng hợp từ [5].

Thậm chí, các trường đại học trên thế giới đã bắt đầu áp dụng phương pháp dạy-học ngẫu nhiên, sinh viên có thể học mọi lúc, mọi nơi, với các phương pháp dạy-học khác nhau thông qua nền tảng công nghệ thông tin và môi trường giáo dục được cung cấp để tích hợp các chứng chỉ micro-nano [8]. Đặc biệt, giáo dục cá thể hóa có thể hỗ trợ học tập suốt đời rất hiệu quả. $T$ - phuoong pháp dạy-học có tuoong tác là một thế mạnh của công nghệ Web 2.0 "Web đọc - viết", "Web hướng con người - xã hội", "Web hai chiều" đến kết nối những người sử dụng web để người dùng có thể đọc, viết và trao đổi được với nhau ở một mức độ nhất định. Đây là cơ sở cho e-learning 2.0 được phát triển và ứng dụng để tổ chức học tập có tương tác, thông qua các dự án khám phá tri thức với học liệu mở. Với cách tổ chức như vậy, việc học tập có thể được thực hiện khắp nơi, với đầy đủ nội hàm của đại học 2.0. Do đó, có thể khái quát hoá đây là giai đoạn chuyển từ quá trình e-learning (với nghĩa Learning everywhere) thành we-learning (với nghĩa Learning everywhere With everybody) [21]. Đây cũng là cơ sở để mở rộng và tăng cường phương pháp dạy-học hợp tác. Vào đầu thế kỷ này, nhiều trường đại học đã áp dụng website môn học. Trên hệ thống đó, người học không chỉ được cung cấp các tài nguyên, học liệu, bài tập về nhà,... mà còn được kết nối, trực tiếp trao đổi và nắm bắt được các trao đổi học thuật của nhóm sinh viên và giảng viên tham gia môn học. Ngày nay, bên cạnh các phần mềm và hệ thống chuyên dụng, các hệ thống mạng xã hội 
cũng hỗ trợ tương tác của các nhóm môn học rất hiệu quả. Tương tác trên các hệ thống công nghệ thông tin là phương tiện để thúc đẩy sự chia sẻ thông tin và xây dựng văn hóa chia sẻ. Tuy nhiên, công nghệ thông tin, đặc biệt là công nghệ số cũng có mặt trái của nó trong việc bảo mật thông tin cá nhân và bản quyền, sở hữu trí trí tuệ. Do đó, cùng với văn hóa chia sẻ phải xây dựng văn hóa trích dẫn và đạo đức khoa học chuẩn mực.

$H$ - Về hạ tầng số, phải đảm bảo hạ tầng pháp lý, hạ tầng nhân lực, hạ tầng kỹ thuật, hạ tầng dữ liệu và hạ tầng ứng dụng [13].

Về hạ tầng pháp lý, cùng với các quy định của các cơ quan quản lý nhà nước, các cơ sở giáo dục đại học cần xây dựng các văn bản quy định, hướng dẫn và các chế tài trong việc phát triển tài nguyên số, truy cập mở, đào tạo trực tuyến, học tập cá thể hóa, văn hóa chia sẻ và đạo đức học thuật. Đặc biệt phải có giải pháp để tăng cường nhận thức về đại học thông minh và chính sách đầu tư hiệu quả.

Về hạ tầng nhân lực, cần quan tâm đến năng lực số, văn hóa số, văn hóa chia sẻ và có kế hoạch tập huấn, bồi dưỡng và trang bị các công cụ cần thiết để giảng viên, nhân viên, người học và các bên liên quan có khả năng tham gia và đóng góp hiệu quả vào quá trình chuyển đổi số.

Hạ tầng dữ liệu được tạo ra liên tục ở khắp nơi, cả dữ liệu có cấu trúc và dữ liệu phi cấu trúc. Nếu như trước đây thách thức về dữ liệu là việc lưu trữ và quản lý thì hiện nay đó chỉ còn là thách thức về việc biến dữ liệu thành thông tin và tri thức có giá trị. Dữ liệu không chỉ được quản lý ở các bộ phận, đơn vị tách biệt mà chính việc kết nối dữ liệu giữa các bộ phận tách biệt đó mới tạo ra giá trị lớn. Dữ liệu không chỉ là công cụ để tối ưu hoá các quá trình mà là tài sản vô hình để tạo ra giá trị. Đối với các cơ sở giáo dục đại học, các dữ liệu quan trọng bao gồm dữ liệu về các nguồn lực (con người, tài chính, cơ sở vật chất), tài nguyên học liệu, quá trình và kết quả dạy-học, năng suất và chất lượng nghiên cứu,...

Hạ tầng kỹ thuật số chủ yếu là các hệ thống máy tính và kết nối mạng đảm bảo dữ liệu lớn và tốc độ truyền thông cao. Đó còn là các trang thiết bị liên quan, các tòa nhà, phòng học, khuôn viên thông minh và các hạ tầng dịch vụ hỗ trợ đào tạo, quản trị thông minh.

Hạ tầng ứng dụng là các phần mềm và công nghệ số và đặc biệt là các công nghệ số chuyên dụng cho từng lĩnh vực cho phép khai thác dữ liệu số để thay đổi phương thức quản lý và tổ chức các hoạt động.

\section{4. Đối sánh mức độ đáp ứng đại học thông minh}

Về nguyên tắc, mức độ đáp ứng và chất lượng của đại học thông minh được đánh giá bằng sự tích hợp của hai kết quả về mức độ thông minh $(C \mathrm{i})$ và mức độ sẵn sàng $(R \mathrm{i})$. Như đã minh họa trên hình 8 , đại học thông minh xuất sắc thường được xác định khi cả $\mathrm{C}$ và $\mathrm{R}$ ở trên mức 3 . Với $\mathrm{C}$ và $\mathrm{R}$ ở dưới mức 3 , nói chung đấy vẫn chủ yếu là đại học truyền thống. Khi $\mathrm{R}>3$ nhưng $\mathrm{C}<3$, đại học vẫn hạn chế về mức độ thông minh, còn khi $\mathrm{C}>3$ và $\mathrm{R}<3$ thì đấy là đại học đã hội đủ các yếu tố thông minh nhưng tỷ lệ giảng viên và cán bộ quản lý tham gia còn ít, các hoạt động chưa được tiêu chuẩn hóa, định lượng hóa và cải tiến, phát triển (Hình 8).

Mức độ thông minh

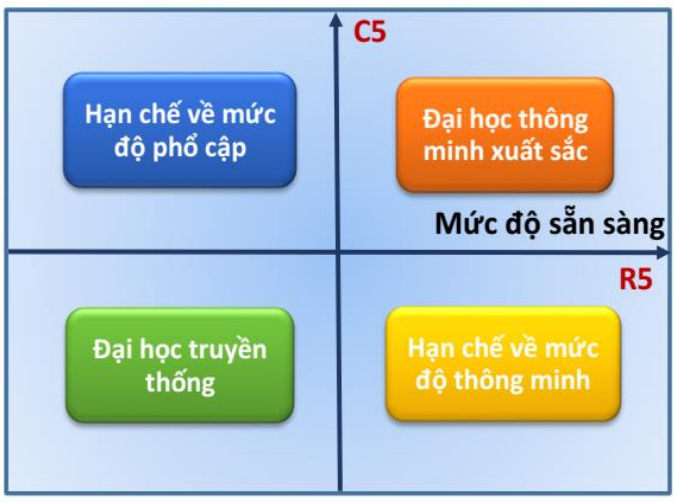

Hình 8. Đối sánh mức độ đáp ứng đại học thông minh.

Trong khi các hoạt động đào tạo, nghiên cứu và chuyển giao tri thức và phục vụ cộng 
đồng đã được đánh giá, đối sánh và xếp hạng đã được triển khai khá hiệu quả thì vấn đề đo lường, đánh giá mức độ thông minh của đại học vẫn còn khá mới mẻ. Bảng xếp hạng Webometrics đã có cơ sở dữ liệu của hầu hết các cơ sở giáo dục đại học ở trên thế giới, nhưng chủ yếu tập trung vào tài nguyên số (mở) và mức độ công bố khoa học trên các tạp chí trực tuyến thuộc hệ thống Scopus.

Bảng xếp hạng đối sánh, gắn sao QS Star đã đề cập đến hạ tầng công nghệ thông tin và dạy học trực tuyến với các tiêu chí:

- Hạ tầng công nghệ thông tin: Trung bình 1 trên máy tính cho 5 sinh viên hoạc truy cập internet ở nơi cư trú của sinh viên hoạc truy cập WIFI đạt từ $60-90 \%$ diện tích khuôn viên (không bao gồm công viên và sân thể thao).

- Công nghệ: Sử dụng công nghệ mới nhất trong dạy - học.

- Quản lý quá trình: Tổng thời gian các khóa học trực tuyến đã được thực hiện.

- Học tập có tương tác: tần suất tương tác giữa sinh viên và giảng viên môn học.

- Bài giảng điện tử: Số lượng các chương trình, bài giảng trực tuyến.

- Uy tín: Số lượng các cơ sở giáo dục đại học khác sử dụng bài giảng điện tử, tài nguyên số của đơn vị.

Bảng 2. Mười tiêu chí trong tiêu chuẩn công nghệ thông tin và tài nguyên số của Bộ công cụ UPM đối sánh chất lượng đại học thông minh [8].

\begin{tabular}{|c|c|c|}
\hline TT & Tiêu chí & Nội dung \\
\hline 1 & $\begin{array}{l}\text { Năng lực kết } \\
\text { nối thông tin }\end{array}$ & $\begin{array}{l}\text { Năng lực thu nhận và quản lý thông tin về tất cả đối tượng và } \\
\text { trên mọi địa điểm trong khuôn viên đại học. }\end{array}$ \\
\hline 2 & $\begin{array}{l}\text { Khả năng phân } \\
\text { tích và quản trị } \\
\text { chất lượng }\end{array}$ & $\begin{array}{l}\text { Cơ sở dữ liệu và các phần mềm thống kê các lĩnh vực cơ bản: } \\
\text { đào tạo, khoa học và công nghệ, cán bộ, tài chính, CSVC, người } \\
\text { học và CSDL đảm bảo chất lượng. }\end{array}$ \\
\hline 3 & Tài nguyên số & $\begin{array}{l}\text { Số lượng tài liệu học thuật nội sinh và các tài liệu học thuật } \\
\text { được số hóa có bản quyền tính trung bình trên tổng số giảng } \\
\text { viên. }\end{array}$ \\
\hline 4 & $\begin{array}{l}\text { Mức độ sử } \\
\text { dụng tài } \\
\text { nguyên số }\end{array}$ & $\begin{array}{l}\text { Tần suất truy cập tài nguyên học liệu thống kê từ các công cụ } \\
\text { phân tích chuyên dụng của các thư viện hoặc Trung tâm học } \\
\text { liệu. }\end{array}$ \\
\hline 5 & $\begin{array}{l}\text { Mức độ tương } \\
\text { tác học thuật }\end{array}$ & $\begin{array}{l}\text { Thống kê tần suất kết nối, tương tác trung bình giữa giảng viên } \\
\text { với các sinh viên thuộc nhóm môn học. }\end{array}$ \\
\hline 6 & $\begin{array}{l}\text { Bài giảng điện } \\
\text { tử }\end{array}$ & $\begin{array}{l}\text { Số lươ̛ng bài giảng online hoặc/và } \mathrm{MOOC} \text { cùng với các liên kết } \\
\text { cần thiết được thể hiện trên cống thông tin của trường. }\end{array}$ \\
\hline 7 & $\begin{array}{l}\text { Ứng dụng hệ } \\
\text { thống thực - ảo } \\
\text { (CPS) }\end{array}$ & $\begin{array}{l}\text { Tỉ lệ số PTN thực hành ảo hoặc hệ thống tương tự có bản quyền } \\
\text { đang được sử dụng trong đào tạo. }\end{array}$ \\
\hline 8 & $\begin{array}{l}\text { Hê̂ thống mạng } \\
\text { không dây }\end{array}$ & $\begin{array}{l}\text { Mức độ phủ wifi tính trên diện tích khu giảng đường, thư viện } \\
\text { và khu hành chính. }\end{array}$ \\
\hline 9 & $\begin{array}{l}\text { Kiểm tra trùng } \\
\text { lặp thông tin }\end{array}$ & $\begin{array}{l}\text { Sử dụng phần mềm có bản quyền có chức năng kiểm tra sự } \\
\text { trùng lặp thông tin và đạo văn. }\end{array}$ \\
\hline 10 & $\begin{array}{l}\text { Chỉ số } \\
\text { Webometrics }\end{array}$ & $\begin{array}{l}\text { Đánh giá khả năng truy cập mở các tài liệu hộc thuật và xuất } \\
\text { bản trực tuyến của trường được công bố trên website }\end{array}$ \\
\hline
\end{tabular}




CÔNG NGHỆ THÔNG TIN VÀ TÀl NGUYÊN SỐ
Năng lực kết nối thông tin phục vụ quản lý
Khả năng phân tích, quản trị chất lượng

Hình 9. Kết quả đối sánh các tiêu chí công nghệ thông tin và tài nguyên số theo Bộ tiêu chuẩn UPM do nhóm nghiên cứu thực hiện cho Trường Đại học Công nghệ, ĐHQGHN. Nguồn upm.vn [8].

Ở Việt Nam, đã có một số nghiên cứu về trường học thông minh, nhưng chủ yếu tập trung vào định nghĩa và đặc điểm của các trường phổ thông $[9,10]$. Mới đây, Nguyễn Hữu Thành Chung và đồng nghiệp [8] đã đề xuất bộ tiêu chí UPM đánh giá mức độ đáp ứng mô hình đại học thông minh định hướng đồi mới sáng tạo. UPM có 8 nhóm tiêu chuẩn và 53 tiêu chí, trong đó có 1 nhóm tiêu chuẩn với 10 tiêu chí về công nghệ thông tin và tài nguyên số. Mặc dù UPM có mong muốn đối sánh cho đại học thông minh, nhưng đối với tình hình phát triển hiện nay của các cơ sở giáo dục đại học Việt Nam, nên bắt đầu từ ba yếu tố cốt lõi của là hạ tầng ứng dụng số (thu thập, quản lý dữ liệu và dạy-học trực tuyến) và hạ tầng dữ liệu (số hóa, đặc biệt là phát triển học liệu số). Do đó, theo bảng 2, trong tiêu chuẩn 6 của UPM các tiêu chí này không tiếp cận đến hạ tầng pháp lý số, hạ tầng nhân lực và hạ tầng công nghệ kỹ thuật số (thuộc các tiêu chuẩn khác trong UPM) của thành phố thông minh và đại học thông minh mà chỉ tập trung đo lường, đánh giá mức độ thu nhận và xử lý thông tin phục vụ quản lý chất lượng, mức độ phát triển tài nguyên số và bài giảng điện tử, mức độ sử dụng tài nguyên số và tương tác trong lớp môn học. Đặc biệt, để phù hợp với xu thế phát triển của Cách mạng công nghiệp 4.0, UPM bắt đầu kiểm đếm mức độ ứng dụng của các hệ thống $\mathrm{CPS}$ vào giảng dạy và nghiên cứu. Hơn thế nữa, trong thời kỳ bùng nổ thông tin số, vấn đề bản quyền và đạo đức khoa học cũng đã được đề cập. Chỉ số xếp hạng Webometrics không chỉ hỗ trợ cho việc đánh giá tài nguyên số mà còn phản ánh năng suất và chất lượng nghiên cứu khoa học trong thời đại số. 
Đối chiếu với các vấn đề đã được khái quát ở trên về đại học thông minh, tiêu chí 1 của UPM thực chất là mức thông minh cơ bản $\mathrm{C} 1$. Các mức độ thông minh C2-C5 đối với hoạt động quản lý chất lượng đã được tích hợp vào tiêu chí 2 . Tiêu chí 3 và 6 hoàn toàn tương đồng với yếu tố $S$ (tài nguyên số) trong mô hình V-SMARTH. Còn tiêu chí 7 có liên quan đến yếu tố A (ảo). Trong bộ tiêu chuẩn UPM, mức độ sẵn sàng được đánh giá thông qua chỉ số tần suất và số lượng của các hoạt động.

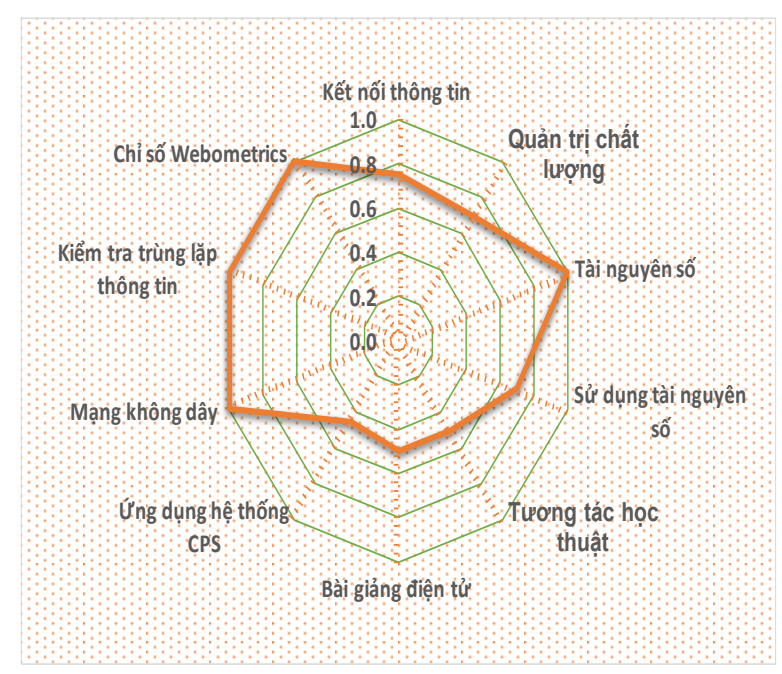

Hình 10. Biểu đồ mạng lưới đối sánh chất lượng ứng dụng công nghệ thông tin và Tài nguyên số của

Trường Đại học Công nghệ, ĐHQGHN.

Triển khai áp dụng bộ tiêu chí UPM cho một số cơ sở giáo dục đại học Việt Nam, có thể nhận xét rằng, đối với các tiêu chuẩn về quản trị chiến lược, đào tạo, nghiên cứu, thậm chí cả tiêu chuẩn về đổi mới sáng tạo, một số cơ sở đã có thể đạt đến mức 4 hoặc 5 sao, nhưng tiêu chuẩn về công nghệ thông tin và tài nguyên số mới chủ yếu đạt mức 3 hoặc 4 sao, trong đó bất cập lớn nhất không chỉ là do các cơ sở giáo dục đại học mới triển khai bước đầu mà còn là vấn đề thói quen quản lý theo hiện tượng, không quản lý định lượng.

Hình 9 và 10 , minh họa kết quả đối sánh tiêu chuẩn công nghệ thông tin và tài nguyên số của UMP cho Trường Đại học Công nghệ, ĐHQGHN. Đây là trường đại học có tài nguyên số trên websie của trường và thư viện dùng chung của ĐHQGHN rất phong phú về số lượng, có chỉ số xếp hạng Webometrics cao. Trường đã chủ động xây dựng bộ công cụ để quản lý mức độ truy cập tài nguyên số và mức độ tương tác của nhóm môn học trên website môn học. Về mức độ tin học hóa, trường là hình mẫu về dịch vụ sinh viên một cửa của ĐHQGHN. Tuy nhiên, Trường Đại học Công nghệ, ĐHQGHN vẫn còn hạn chế về số lượng bài giảng điện tử (ở mức cao), tần suất tương tác giữa giảng viên và sinh viên trong nhóm môn học và mức độ ứng dụng các hệ thống thực ảo còn khiêm tốn.

\section{Kết luận}

Mô hình khái niệm về đại học thông minh đã được tổng quan và khái quát hóa với mô hình V-SMARTH, bao gồm 6 thành tố và hoạt động cơ bản (tài nguyên số, học liệu truy cập mở, môi trường dạy-học ảo, đáp ứng nhu cầu học tập riêng, phương pháp dạy-học có tương tác và hạ tầng số) qui tụ trong ba trụ cột: Số hóa, đổi mới mô hình dạy-học dựa trên công nghệ số và chuyển đổi số toàn diện từ tư duy đển văn hóa, lãnh đạo, quản lý và điều hành. Nghiên cứu này cũng đã tiếp cận đến khái niệm về mức độ thông minh và mức độ sẵn sàng của đại học thông minh. Đặc biệt, vấn đề đo lường và đối sánh chất lượng của đại học thông minh đã được thử nghiệm với bộ tiêu chuẩn UPM. Các đề xuất trong nghiên cứu này có tính cơ bản và hệ thống, có thể áp dụng để triển khai thực hiện đồng thời quản trị quá trình chuyển đổi số nói chung và xây dựng đại học thông minh cho các cơ sở giáo dục đại học ở Việt Nam.

\section{Lời cảm ơn}

Công trình nghiên cứu này được tài trợ bởi Chương trình KH\&CN về Khoa học Giáo dục cấp quốc gia với đề tài: Nghiên cứu mô hình trường đại học đáp ứng Cách mạng công nghiệp 4.0 ("Đại học 4.0") mã số KHGD/1620.ĐT.007. 


\section{Tài liệu tham khảo}

[1] L. Vladimir, Uskov, P. Jeffrey, Bakken, J. Robert, Howlett, C. Lakhmi, Jain, Smart Universities: Concepts, Systems and Technologies, Springer, 2018.

[2] Smarter education with IBM. https://www935.ibm.com/services/multimedia/FrameworkSmarter-Education-With-IBM.pdf/, 2020 (accessed 15 March 2020).

[3] T. Roth-Berghofer, "Smart university, the university as a platform", Disponível em. https://smartuniversity.uwl.ac.uk/blog/?p=100/, 2013 (accessed 15 March 2020).

[4] Mauro Coccoli, Angela Guercio, Paolo Maresca, Lidia Stanganelli, Smarter universities, A vision for the fast changing digital era, Journal of Visual Languages and Computing 25 (2014) 1003-1011.

[5] UNESCO-Education Sector, Classroom revolution through SMART education in the Republic of Korea - Case study by the UNESCOFazheng project on best practices in mobile learning, UNESCO, 2019.

[6] Nguyen Huu Duc, Nguyen Huu Thanh Chung, Nghiem Xuan Huy, Mai Thi Quynh Lan, Tran Bich Lieu, Ha Quang Thuy, Nguyen Loc, Towards the Higher Education 4.0 Characteristics and Criteria, VNU Journal of Science: Policy and Management Studies 34(4) (2018) 1-28. https://doi.org/10.25073/25881116/vnupam.4160 (in Vietnamese).

[7] Nguyen Quy Thanh và Ton Quang Cuong, New technology trends in education, http://hdll.vn/vi/thong-tin-ly-luan/nhung-xu-the-moicua-cong-nghe-trong-giaoduc.html?fbclid=IwAR1yN12vlNBk8d4TyQw1D6_ fgIXmwiqjPVKeiMHRqGz-NaUTygw61brfo3s/, 2019 (accessed 11 March, 2020).

[8] Nguyen Huu Thanh Chung, Tran Van Hai, Vu Thi Mai Anh, Nghiem Xuan Huy, Ta Thi Thu Hien, Nguyen Huu Duc, SMARTI University Model and Performance Benchmarking System UPM, VNU Journal of Science: Policy and Management Studies 36(1) (2020) 28-43 (in Vietnamese).

[9] $\mathrm{Vu}$ Thi Thuy Hang, Smart school: Origin, definition and proposals for Vietnam, Journal of Education 432 (2018) 6-10 (in Vietnamese).
[10] Nguyen Manh Hung, Tran Khanh Duc Eds, 4.0 Smart School Governance and QS University Rangking, Vietnam National Unievrsity Press, 2020 (in Vietnamese).

[11] Smart City, https://forbesvietnam.com.vn/congnghe/khai-niem-thanh-pho-thong-minh-o-vietnam-co-gi-khac-so-voi-the-gioi-4747.html/, 2020 (accessed 15 March 2020).

[12] Smart University, http://su.disi.unitn.it/, 2019 (accessed 15 December 2019).

[13] Ho Tu Bao, Basic concepts of the digital transformation.

http://www.jaist.ac.jp/ bao/talk/CauhoiveChuyendoi so.pdf?fbclid=IwAR0Cy01uJllYqn90Kw93IRVJYz uYJOOc9VqzUym5E3O7NKV-wJD1EYMgp4k/, 2020 (accessed 15 March 2020).

[14] S. Chun, Korea's smart education initiative and its pedagogical implications, CNU J. Educ. Stud. 34(2) (2013) 1-18.

[15] Vladimir L. Uskov, Robert J. Howlett, Lakhmi C. Jain, Smart Education and e-Learning 2016, Springer, 2016.

[16] Behrad Bagheri, Big future for cyber-physical manufacturing systems, Design World, September 23, 2015.

[17] Kuo-Ming Chao, Cyber Physical Systems for Future Higher Education, Coventry University, UK, private communication, 2018.

[18] CMMI (Capability Maturity Model Integration), https://sultanalmasoud.files.wordpress.com/2014/ 05/cmmi-pyramid.gif/, 2014 (accessed 11 December 2019).

[19] Colleen Heinemann and Vladimir L. Uskov, Smart University: Literature Review and Creative Analysis, 2018, pp. 11-46.

[20] Sahar Yassine, Seifedine Kadry, Miguel-Ángel Sicilia, Measuring learning outcomes effectively in smart learning environments, Published in Smart Solutions for Future Cities, 2016. https://doi.org/10.1109/SSFC.2016.7447877.

[21] Fehmida Hussain, E-learning 3.0 = E-learning 2.0 + Web.3.0, IADIS International Conference on Cognition and Exploratory Learning in Digital Age (CELDA 2012), 2012. 